\title{
DIE KONINGSKAP IN ISRAEL
}

Eweas by soveel ander volkere van die wêreld het die tydvak van staatkundige grootheid van Israel begin aanbreek in 'n periode van nasionale verdrukking en verknegting. Sedert die vestiging in Kanaän het die eenheid van die volk, wat versterk is deur die verbondsluiting te Sinai en die daaropvolgende woestynreis, enigsins verlore gegaan, deurdat die stamme versprei is en elkeen sy erfdeel in besit geneem het. Die inbesitneming van die land het op tweërlei wyse geskied, langs die weg van verowering met geweld en deur vreedsame verdragsluiting. ${ }^{1}$ ) Tussen die Israelitiese stamme het die oorspronklike bewoners gevestig gebly, selfs tot aan die regering van Dawid: 2 Sam. 5, 6v. As gevolg van die verspreidheid van die stamme oor die hele land was daar van 'n gemeenskaplike optrede of handeling geen sprake nie. Die gesag van die Rigters was alleen beperk tot enkele stamme, wat op die oomblik in gemeenskaplike gevaar verkeer het. Die Rigtereboek verhaal dan ook van voortdurende botsinge tussen Israel en die volkere in wie se midde hulle woon, dog telkens is dit alleen bepaalde stamme wat hulle moet verweer teen vyandelike aanvalle: Rigt. 3, 4, $6-8,10.11$. Nergens vind ons dat die hele volk gesamentlik optree nie, omdat die sentrale gesag en leiding ontbreek.

Juis in hierdie tyd het daar 'n nuwe gevreesde vyand sy verskyning gemaak en wel die Filistyne (Pelisjtim, vandaar die naam Palestina), wat in die eerste helfte van die twaalfde eeu uit Kreta en ander eilande van die Middellandse See, asook van die weskus van KleinAsië Palestina binnegedring het. Die tyd was vir hierdie invallers besonder gunstig. ,Zij vulden in Palestina een politiek vacuum"2). Die mag van die groot omliggende wêreldryke, die Hetiete, Egipte en Assirië het gedaal tot 'n laagtepunt. Die Filistyne het by hul invalle weinig of geen teenstand ondervind nie, maar het hulle spoedig aan die kusstrook gevestig en hul mag hiervandaan uitgebrei. Van hierdie gedugte en gedissiplineerde krygsvolk het Israel in hierdie en die volgende tyd veel te verduur gehad. Nie alleen in die rigting van die minder vrugbare Judese bergland het hulle voortgedring nie, maar ook die hande uitgestrek na die ryker gebied van Efraim, meer Noord geleё, en selfs tot aan die Vlakte van Jisreël. Waar die druk aanvanklik slegs van tydelike en plaaslike aard was, het dit mettertyd groter afmetings aangeneem; dit het meer algemeen en van blywende aard geword. Verskillende Israelitiese stede is verwoes o.a. ook

1) R. KItTel, Geschichte des Volkes Israel, 1 Band. Gotha, Leopold Klotz, 1923. p. $420 \mathrm{v}$.

2) Тон. DE Groot, I Samuel. Tekst en Uitleg. Groningen, Wolters, 1934, p. 18 
Silo waar die heiligdom was: Jer. $7: 12-14$; die verbondsark geraak in die hande van die Filistyne en die priesters Hofni en Pinehas kom om: 1 Sam. 4:11. Verder monopoliseer die oorheersers die yster sodat geen wapentuig gesmee kon word nie; selfs vir hulle landbouwerktuie was die Israeliete aangewys op die oorheersers: 1 Sam. 13:19-22. Binne Israelitiese gebied word 'n Filistynse landvoog in Gibeon aangestel: 1 Sam. 10:5, 13:3v. Al swaarder en swaarder het die hand van die verdrukker hom laat voel.

Dog die verslae volk het nie alleen van die Filistynse te lye gehad nie. Van oorkant die Jordaan het daar 'n nuwe bedreiging gekom in die Ammoniete onder Nahas: 1 Sam. 12:12, 'n volk wat verwant was aan Israel. Dit was nie die eerste keer dat Israel en Ammon met mekaar in aanraking gekom het nie. Reeds in die dae van die Rigters het Jefta hom teen hulle moes verweer: Rig. 10v.

So het die gevaar van weerskante op hulle aangestorm. Dit was nou nie langer alleen enkele stamme wat gely het, of gedreig het om onder te gaan nie, die lot en die toekoms van heel Israel was nou hiermee gemoeid. Dit was duidelik waaraan hierdie katastrofe te wyte was, nl. aan die verbrokkeling van kragte en innerlike verdeeldheid. Gebrek aan samewerking het doeltreffende verweer onmoontlik gemaak. Wat Israel nodig gehad het, was 'n sentrale gesag, 'n sterk hand, in koning rondom wie nie alleen enkele stamme hulle sou skaar nie, maar die volk as geheel_., n koning wat ons kan rig en voor ons uittrek en ons oorloë voer" (I Sam. 8:20).

In hierdie tyd van nasionale en religieuse nood het Samuel na vore gekom. Onafskeidelik is sy naam dan ook verbind aan die ontstaan van die koningskap in Israel. Die berigte in $1 \mathrm{Sam} .8-12$ verhaal hoedat Samuel die hooffiguur is, nie slegs by die instelling van die koningskap nie, maar ook by die keuse van die koning. By nadere beskouing en noukeurige ontleding van die berigte in die betreffende hoofstukke blyk duidelik twee teenoorgestelde gedagtereekse, 'n tweevoudige beoordeling van die koningskap. Volgens die een berig is dit ' $n$ instelling ooreenkomstig Gods wil, 'n dwinggende noodsaaklikheid om Israel te red van sy innerlike verskeurdheid en van die dreigende ondergang as gevolg van die vreemde oorheersing: 1 Sam. 9:16. Van heeltemal ander aard is die tweede beskouing. Hier is die eis om 'n koning 'n uitvloeisel van die verblyf tussen die vreemde volkere, afval van die ware koning, God. Samuel verset hom hierteen en dit word deur hom eers uitgevoer as God hom uitdruklik opdra om die weerbarstige volk in sy goedheid tog tegemoet

3) P. Volz, Prophetengestalten des Alten Testaments. Stuttgart, Caluer Verein, 1938. p. 77.

1) W. EICHrodt, Theologie des Alten Testaments. Bandl. Leipzig, J. C. Hinrichs. 1933 , p. 237. 
te kom. Volgens die een gedagtereeks is God, profeet en volk eenstemmig betreffende die noodsaaklikheid van die koningskap, dit is 'n uitkoms en 'n seen. Anders gesien is die instelling hiervan ' $n$ afbuiging van die tot dusver bewandelde weg van trou en gehoorsaamheid aan God.

Hoe moet ons nou hierdie tweevoudige beoordeling, hierdie teenstrydigheid binne die berigte verklaar? Gewoonlik is aangeneem dat die oudste opvatting die was van positiewe waardering van die koningskap, dat Samuel goedkeurend hierteenoor gestaan het, dog dat die latere misstande onder Salomo en sy opvolgers daartoe aanleiding gegee het, dat daar minder gunstig oor die koningskap geoordeel is. Wat dan teenswoordig naasmekaar in die verhale voorkom, sou oorspronklik namekaar gewees het. Tereg wys $V_{\text {olz }}^{3}$ ), asook Eichrodt') daarop dat ons reeds vanaf die begin van die koningskap moet rekening hou met beide standpunte. Die beoordeling van die koningskap ten tyde van sy instelling is reeds tweevoudig. Israel was ook, wat hierdie saak betref, nie eenstemmig nie. Daar was die gewees wat heeltemal verwêreldlik het, wat alleen heil gesien het in 'n koning, en wel 'n koning soos bekend was by die omwonende volk "dat ons ook kan wees soos al die nasies": 1 Sam. 8:20. Daar was verder die wat vasgehou het aan die verkiesingsgedagte, maar wat geglo het dat in staatkundige opsig hulle hul tog wel moes aanpas by die ander volkere. Dan was daar 'n derde groep, die meer profetiese geeste wat uitgegaan het van die koningskap van God, dat Hy self die opperste leidsman van Israel is, nie alleen wat religieuse sake betref nie, maar ook in die politiek en in die oorloë. De beswaar teen die koningskap is dus godsdienstig van aard. Die oordeel oor die koningskap as ' $n$ anti-goddelike instelling is suiwer religieus te verstaan. Die verskil tussen die Godsvolk en die buurvolkere is hier duidelik merkbaar. Elders is die koning stadhouer van God, seun van God. In Israel is die koning beskou as konkurrent van God. Gideon het reeds uitdrukking gegee aan daardie religieuse besef in Israel, toe hy die koningskap afgewys het met die woorde: „Ek wil nie oor julle heers nie, en ook my seun mag oor julle nie heers nie: die Here sal oor julle heers": Rig. 8:23.

Hierdie dinge was oorsaak dat ondanks die drang van omstandighede die verlange na 'n koning slegs aarselend tot uiting gekom het. Daar is instinktief gevoel dat deur aan te dring op 'n koning, daardeur tot uiting kom 'n gebrek aan vertroue op God. 'n Aardse koning pas sleg in die kader van Israel se volksbestaan. In Israel is God self koning. „Er zijn dus twee lijnen in die zaak van het koningschap, twee gedachtenreeksen, die elkaar eigenlik uitsluiten. De nationáalpolitieke geest eischt het koningschap, de nationaal-religieuze geest verzet zich. In den tijd der benauwdheid won de nationaal-politieke 
geest, maar in die ontwikkeling van Israels koningschap zou spoedig blijken dat Jotams fabel meer dan een fabel was geweest en dat het koningschap niet alleen maar een politieke kwestie was." ${ }^{\circ}$ )

Om hierdie teenstand van die profetiese geeste teen die koningskap goed te begryp, is dit nodig om ons rekenskap te gee van die aard en karakter van die Oosterse koningskap. In die hele Oosterse wêreld is die koning allereers 'n religieuse figuur en daaruit vloei voort sy politieke funksie en verpligtinge. Die koning is nie maar 'n gewone mens nie, hy staan tussen God en mens, hy word ook die ewebeeld van God genoem. Van eminente heersers o.a. Gilgames word verhaal dat hy twee-derde God en een-derde mens is. ${ }^{6}$ ) Die koning is godeseun en kragtens sy posisie is hy middelaar tussen God en mens. Deur die koning regeer God die volk, die koning is Sy gevolmagtigde, Sy plaasvervanger. Vanuit hierdie standpunt was dit maar 'n klein skrede om te kom tot vergoddeliking van die koning soos dan ook meermale in Egipte en Babel gebeur het. Hieruit volg dan noodwendig dat die keuse van 'n koning nie by die volk berus nie, maar dat hy deur God self aangewys word, vgl. 1 Sam. 9:16.

Hierdie Oosterse god-koning-gedagte het slegs ingepas by die Israelitiese monoteïsme. Menslik gesproke was dit onmoontlik om koning te wees in Israel. ${ }^{7}$ ) Dit is deur die beste deel van die volk gevoel en daaruit het voortgespruit die verset teen die koningskap. Nou het die karakter van die Israelitiese koningskap wel verskil van dié by die Oosterse volkere, sowel as van die klein stadkoninkies in Kanaän. Die uitgangspunt egter was ook vir Israel die voorhande bekende materiaal. Israel was deel van die ou kultuurwêreld en het gebruik gemaak van die uitdrukking en voorstellingsvorme wat daar gangbaar was. Onder die invloed van die monoteïsme het daar wel verskuiwinge plaasgevind, maar iets daarvan het tog ook in Israel bly naklink, vgl. 11 Sam. $7: 14$, Ps. $2: 7$, Ps. 72, Ps. $89: 28$, Ps. $45: 7,8$. Wat was nou Samuel se houding? Wat ons van Samuel weet as profeet, verwag ons dat hy hom van die begin af verset teen hierdie eis van die volk. Dit blyk dan ook duidelik uit I Sam. 8, 10:18v., 12. Die teenstelling tussen die opvatting van Samuel en die wil van die volk blyk veral in Sam. 8:5, waar die volk sê: "Stel nou 'n koning oor ons aan om ons te rig soos al die nasies", en in Sam. 8.20: "ons wil soos al die nasies wees." Daar moet geen onderskeid wees tussen Godsvolk en ander volkere nie, hy wil by die nasies gereken wees. Sy roeping as afgesonderde volk soos o.a. beliggaam in die Bileamspreuk, sê die volk vaarwel: Num. 23:10. Vir die profeet is die

5) H. T. Obbink en A. M. Brouwer, Inleiding tot den Bybel. Amsterdam, H. J. Paris, 1928, p. 37.

c) B. Meissner, Babylonien und Assyrien. 1 Band. Heidelberg, Carl Winter, p. 46.

) EICHRODT, p. 237. 
instelling daarom iets anti-goddeliks omdat dit indruis teen die gees van Israel as Godsvolk. Israel boet hiermee sy karakter as gōj qadōsj. heilige volk, in, omdat hy wil wees soos ander volke wat 'n koning het. Wanneer die koningskap nou tog ingestel word, trots die teenkanting van Samuel, as in toegewing aan die volkswil, dan staan Samuel by. Die invoering geskied deur die profeet, dit is ' $n$ historiese gebeurtenis en so ontstaan die berigte in I Sam. 9, 10:1-16, 11 $14 \mathrm{v}$., waar van teenkanting deur Samuel nie meer melding gemaak word nie. waar dit wil voorkom of hy instem. In eersgenoemde perikope word die vraag betreffende die koningskap prinsipieel belig; in die ander berigte gaan dit oor die instelling van die eerste koning, om die keuse van Saul. In 10:18-24 is die twee verbind.

Uit wat bo gesê is vloei voort watter verwagtings aan die koning gestel is as hy daaraan moes beantwoord om koning in Israel te wees. Sy taak was nie alleen dat hy Israel sou verlos van sy vyand en verdrukkers nie, maar dat hy regeer as verteenwoordiger van God, m.a.w. dat hy sy religieuse amp verstaan. Die meer profetiese geeste en meer bepaald Samuel, laat, as hulle van die onvermydelikheid van die koningskap oortuig is, die koningskap as in sterk charismaties-bepaalde toe (charisma: genade, guns). ${ }^{8}$ ) Die koningskap van Israel is dus geen politieke, maar in charismatiese grootheid. Omdat die koning deur Gods genade daar is, heet hy die Gesalfde van die Here"). Teen hom waag Dawid dit nie om sy hand uit te steek nie: 1 Sam. 24:7.

So het Israel dan sy eerste koning gekry. Aan die begin van die regering van Saul staan twee glansryke dade n.l. die oorwinning oor die Filistyne: 1 Sam. 13, 14, en sy glansryke ekspedisie teen Nahas van Ammon en die daaropvolgende ontset van Jabes in Gilead: 1 Sam. 11. Die skrywer van die Samuelboek sien die oorsaak van Saul se geslaagde optrede hierin, dat die gees van die Here oor Saul vaardig geword het: 1 Sam. $10: 6,10 ; 11: 6$. Uit die eenvoudige, tot nog toe onbekende seun van Kis, het daar nou gegroei 'n kragbewuste leier van die volk, wat alle versaagdheid onder die volk weet te verban, nie deur veldheerstalent of politieke vernuf, nie deur 'n sterk koningsreg of staatsorganisasie om hom te rugsteun nie, maar enkel omdat die gees van die Here hom vervul het. ., On the morning when Samuel annointed him, a new soul had been born in him, and he knew who he was." ${ }^{10}$ ) Die leierskap van Saul word teruggevoer tot die Here of sy gees, en is nie toe te skrywe aan ' $n$ onpersoonlike innerlike krag nie ${ }^{11}$ )

8) EICHRODT, p. 238.

9) L KöHLER, Theologie des Alten Testaments. Tübingen, J. C. B. Mohr, 1936, p. 152.

10) Johs. Pedersen, Israel, its life and culture I-II. London. Humphrey Milford, Oxford University Press. Copenhagen. V. Pio. Povl Branner, p. 185.

11) Pedersen, p. 194. 
Saul toon deur sy aanvanklike optrede dat die gees van die Heer ook hierdie oorspronklike heidense instelling kan deursuur en op die wyse diensbaar maak. In die benaming nagid, vors, is merkbaar die opvatting van die sieners en die profete, in teenstelling met die Kananitiese melek, koning.

Saul se optrede was egter nie daarop bereken om die koningskap in Israel te bestendig nie. Wat by die Rigters met hulle kort lewensduur voldoende was, blyk by die koningskap dit nie meer te wees nie. Behalwe die deur Godbegeesterde persoonlikheid was daar meer nodig. Wat ontbreek het, was 'n geordende staatsmag en 'n staande leër. Tot dusver het beide ontbreek. Eenmaal koning is die charismatiese kant van die amp al meer en meer verdring deur die offisieel-amptelik. Met die verkryging van meer koninklike mag het Saul se wyse van optrede verander asook sy karakter. As Samuel vertoef om na Gilgal te kom, en Saul sewe dae lank wag op sy koms, dan bring hy self die offer voor die slag. Wanneer Samuel dan opdaag en Saul ondervra, dan is die antwoord van die profeet: ,Jou koningskap sal nie bestaan nie, jy het dwaas gehandel. omdat jy nie gehou het wat die Here jou beveel het nie": 1 Sam. 13:8v. Eweso in die Amalekietekryg blyk dit dat Saul die menslike grootheid vooropstel, sy koningsheerlikheid, en nie meer in gehoorsaamheid aan God wil regeer nie. Die verteenwoordiger van God verteenwoordig hom nie meer nie. Daar kom dit tot ' $n$ finale breuk tussen Samuel en Saul. Agag word deur Samuel in teenwoordigheid van Saul, die koning, wat hom begenadig het, tereggestel. Die profeet voer hier die wil van God uit, nie meer die koning nie. Met in koningskap wat roem op sy amptelike mag, in stede van in gehoorsaamheid aan God te handel, het die man van God niks te doen nie. Die koningskap ontleen sy outoriteit nie langer aan die Heer nie, gevolglik is die draer daarvan op hierdie oomblik reeds een wat in die oog van Samuel veroordeel is. Dit is juis die tragiek in die lewe van Saul dat dit hom nie geluk het om hierdie heterogene sye van die koningskap met mekaar te verbind nie.

Ook 'n verandering in sy karakter werk hiertoe mee. Ons hoor nie meer dat die gees van God oor hom vaardig word nie. Hy word gedring in die rigting van 'n gevaarlike opportunisme, waar dit net om sy roem of sukses gaan. Wanneer die oorloë teen die Filistyne nie tot $n$ suksesvolle einde kan kom nie, word hy die prooi van 'n ernstige sielsiekte, by sy reeds swaarmoedige aanleg. Saul het die aanraking met die Heer verloor. "Saul's behaviour is typical of a man who has lost the blessing. Aimlessly he rushes about from one place to another. The tragic pathos of the figure of Saul is not the outward conflict. but the fact that he who had the blessing should loose it. The nar rator has pictured his soul in its growth and strength, and we see how it is gradually emptied out and shrinks, more and more vacillating and 
divided within itself, making plans which are foredoomed to fail, and yet driven afresh to action, because he has to fight in order to maintain his blessing." "') ,De allerdiepste kern van zijn tragedie wordt, dat hij een God heeft, die zwijgt . . . Hy wordt een gevangene in dit leven, met het doodvonnis hangende boven zijn hoofd. En als hij eindelik den onheilspellenden vleugelslag van den engel des verderfs duidelijk hoort, valt hy op de velden van Gilboa als het offer van vreeslijke duistere machten en van het eigen gedeeld bestaan." ${ }^{\prime 3}$ )

Dit is opmerklik dat tenspyte van hierdie pynlike ontnugtering en droewige ervaring met die nuut-gestigte koningskap, die vereerders van die Here hierdie instelling nie prysgee nie. Dit is alleen aan Dawid te danke. Reeds tydens die leeftyd van Saul het Samuel hom na Dawid gewend, en op Gods bevel hom gesalf as koning oor Israel. $\mathrm{Hy}$ is die man na Gods hart, die man van vertroue. Vroeg reeds soek hy aansluiting by die priesterdom van Nob: 1 Sam. 21. Op een van sy vlugte voor Saul voorsien die priesters van Nob hom van voedsel. Dit geluk Dawid dan ook om die charismatiese en amptelike sy van die koningskap te verbind. Deur sy optrede bewys hy dat die koningskap wel bestaanbaar is in Israel. Hy stel ' $n$ goeie verhouding tussen priesterskap en koningskap op prys en weet om sy eerste verpligting as koning n.l. die religieuse te vervul. Nadat hy koning geword het, bring hy die ark oor na Jerusalem, waar 'n nuwe heiligdom ingerig word. Die dienaars by die heiligdom maak hy sy vertrouelinge. Hy self munt uit in sy ywer deur die aanbring van offers, en die voorneme om 'n tempel te bou spreek ten gunste van die plan om sy religieuse amp as koning getrou na te kom: II Sam. 7. Volgens die beeld van Dawid in die Kronieke het die priesterskap hom as een van hulle gereken. Die versterking van sy ryk, die onderwerping van die omwonende volkere, die raadpleging met die oudstes, die verskuiwing van die koninklike residensie van Hebron na Jerusalem, die in die lewe roep van ' $n$ staande mag en die instelling van verskillende amptenare wys alles in die rigting van verstewiging van sy koningskap. Tog het hy die simpatie van die profete bly behou. Hy het hom aan hulle verwant gevoel en hulle waardeer. Die profeet Natan verkondig hom die bestendiging van sy huis, die ewige duur van sy dinastie: II Sam. 7, 'n belofte van die kant van die profeet wat mens kwalik moontlik sou ag na die ervaring met Saul. Die merkbare seën wat Dawid vir die volk meebring, het by hulle die laaste twyfel aangaande die welgevalligheid van die koningskap as duursame instelling uit die weg geruim. Ook die geslaagde onderdrukking van die opstand onder Absalom het wellig bygedra daartoe, dat die profete die voordeel van 'n goed gevestigde dinastie ingesien het. Dawid was die

12) PEDersen, p. 188.

13) De Groot, p. 29, 30. 
koning na Gods hart, 1 Sam. 13:14, hy was koning soos dit behoort te wees. "A King must be blessed with the greatest blessing, because the whole of the people must derive its blessing from him. David was richer in blessing than any other Israelite; his life was one long series of blessings. The blessings all the time took greater and greater effect in David ... . his blessings grew and grew. ${ }^{1 .}$ ) A royal blessing had been given him, his house stood firm, and before he died, he had the happiness of seeing one of his sons his successor." ${ }^{15}$ ) Die Dawidiese regering het die bewys gelewer vir die moontlikheid van die koninklike amp binne die Jahwereligie. ${ }^{16}$ ) Die verdienste van Dawid was dat hy die verskillende religieuse kragte in sy ryk saamgesnoer het en tegelyk 'n hegte staatkundige grondslag gelê het.

Onder Salomo het die koningskap 'n nuwe rigting ingeslaan. Die religieuse grondslag van die koningskap het hy al meer gaan verbind met die sakramenteelkultiese. Kenmerkend hiervan was die bou van die tempel as deel van die koninklike residensiekompleks; die koning is nou onaantasbaar. Meer en meer het hy ook geneig tot die Oosterse absolutisme. Salomo met sy uitheemse neiginge, vreemde vroue, heidense tempels, met sy prag en praal, het kwalik beantwoord aan Israel se ou ideale. Hard is dan ook die oordeel oor Salomo in II Kon. 11:4. Daarby het nog gekom dat sy pragliewendheid die reeds sware laste wat die koningskap meegebring het, nog verder verskerp het. Dit alles het daartoe meegewerk om die sluimerende verset teen die koningskap aan te wakker. Na die oordeel van die profete het die instelling onder Salomo $n$ rigting ingeslaan wat teenstrydig was met die wil en gees van die Heer. en wel die gevaarlike, waarteen reeds Samuel by die begin gewaarsku het. Tog kom dit nog nie tot 'n verwerping van die instelling as sodanig nie. Hoe ook al opgetree word teen afsonderlike konings b.v. Elia teen Agab, word die koningskap tot nog as noodsaaklik vir die volk beskou.

Eers tydens die optrede van die klassieke profete met hul diepere Godskennis word die oorsaak van al die kwaad in die instelling van die koningskap gesien.

Die skerpste veroordeling hiervan vind ons by Hosea, wanneer die Noordelike Ryk reeds sy ondergang tegemoet gaan: Hos. 9:15-17. Die koningskap van Israel is reeds sedert die verkiesing van Saul as n Godevyandige en oproerige gebrandmerk. Naas die Heer is daar geen plek vir sulke aardse heersers nie. Meestal al die sondes wat hy gesel, vind hul oorsprong hierin, vgl. $5: 1,7: 16,8: 9,10: 13-15$, $12: 12$. In Gilgal reeds, daar waar Saul gekroon is, is die lot van die

\footnotetext{
1.4) Pedersen, p. 184, 185.

1.5) Pedersen, p. 190.

16) EICHRODT, p. 241.
} 
volk beseël Toe reeds is die vrugteboom van Efraim in die wortel getref, en in plaas daarvan, soos verwag is, dat Israel deur die koningskap ' $\mathrm{n}$ rol in die wêreld sou speel, vgl. 1 Sam. 8:5, het hy daardeur geword ' $n$ Kain in die volkerewêreld $\left.{ }^{17}\right)$. Heftig is die veroordeling in Hos. 10:3v. Met bittere ironie word verhaal wat die koningskap so al uitgerig het. Die volk is in die maalstroom van die buitelandse politiek ingetrek, en daardeur is die reg vernietig. Diplomatieke onderhandelinge, lojaliteitsversekeringe, koalisies, huldigingsede, dit alles is vir Hosea valse bedrog. Elke verbondsluiting lei weer tot verbondsbreuk. 'n Blik in die geskiedenis van Voor Asie in daardie tyd toon dat die oordeel heeltemal geregverdig is. Vir hierdie tot in die grond verdorwe instelling is daar geen simpatie nie; al wat oorbly, is die volledige vernietiging van hierdie inwendig holle institusie: Hos.3:4, $10: 7,15$.

Gelykluidend met die getuienis van die Noord-Israelitiese profeet is diê van die profete uit Juda. Jesaja stel die vernietiging van die Dawidiese dinastie in die vooruitsig as hy spreek van die stomp van Isai : Jes. $11: 1$. Jeremia en Esegiël wys heen na 'n nuwe toekoms, oor die teenswoordige troostelose koningskap, heen na 'n nuwe koning, deur die Here aangestel: Jer. $23: 5$, Es. $37: 24$. Die profete het in die koningskap, soos dit ontaard het, 'n aantasting van God en sy heerskappy in Israel gesien. Geweeg en te lig bevind, is die slotsom waartoe hulle geraak.

Die koningskap van Israel het misluk. Die konings van Israel het gefaal. Aan die hooggestemde verwagtings kon hulle nie voldoen nie; in hul taak as stadhouers van God het hulle te kort geskiet. Tog mag die skerpste kritiek ons nie blind maak vir wat die koningskap in die volkslewe uitgerig het nie. Voor Israel se oog het die beeld van die ideale koning verrys, wat alles, waartoe die empiriese koning nie in staat was nie, sou verwerklik. God sou self vir Hom die koning kies, wat die koningstitel met eer sou dra, wat waarlik koning sou wees, Seun van God, wat die heilseeu inlui, nie alleen vir Israel nie, maar vir die ganse wêreld.

E. S. Mulder. 